\title{
The risk concept and its application in natural hazard risk management in Switzerland
}

\author{
M. Bründl ${ }^{1}$, H. E. Romang ${ }^{1}$, N. Bischof ${ }^{1}$, and C. M. Rheinberger ${ }^{1,2}$ \\ ${ }^{1}$ WSL Institute for Snow and Avalanche Research SLF, Davos, Switzerland \\ ${ }^{2}$ IED Institute for Environmental Decisions, ETH Zürich, Switzerland
}

Received: 21 October 2008 - Revised: 19 May 2009 - Accepted: 19 May 2009 - Published: 27 May 2009

\begin{abstract}
Over the last ten years, a risk-based approach to manage natural hazards - termed the risk concept - has been introduced to the management of natural hazards in Switzerland. Large natural hazard events, new political initiatives and limited financial resources have led to the development and introduction of new planning instruments and software tools that should support natural hazard engineers and planners to effectively and efficiently deal with natural hazards. Our experience with these new instruments suggests an improved integration of the risk concept into the community of natural hazard engineers and planners. Important factors for the acceptance of these new instruments are the integration of end-users during the development process, the knowledge exchange between science, developers and end-users as well as training and education courses for users. Further improvements require the maintenance of this knowledge exchange and a mindful adaptation of the instruments to case-specific circumstances.
\end{abstract}

\section{Introduction}

Over the last ten years, integrated approaches to manage natural hazards have been developed in Switzerland (PLANAT, 2005; Ammann, 2006) and other European countries (e.g., Jonkman et al., 2008; Merz and Emmermann, 2006). Common denominator of these approaches is the understanding of natural hazard management as a threefold task (Kaplan and Garrick, 1981): (I) the analysis of risk, (II) the evaluation of risk, and (III) the finding of appropriate mitigation strategies sometimes referred to as management of risk. Such a threefold conception of risk, hereafter called the risk concept, was first developed as a decision support framework for dealing

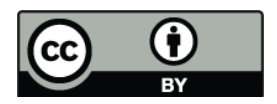

Correspondence to: $\mathrm{M}$. Bründl (bruendl@slf.ch) with complex technical systems such as nuclear power and chemical industry facilities (see Starr, 1969). In the 1980s and 1990s, the risk concept was introduced to the management of natural hazards in order to quantify the degree of hazard. In Switzerland, results of the research program "Risk and Safety" (1990-1995) were the starting point for various publications and instruments (e.g., Merz et al., 1995), which were subsequently transferred to the field of natural hazards (e.g., Heinimann et al., 1998; Hollenstein, 1997). Further, publications by the public authorities provided guidelines and recommendations on how natural hazards should been accounted for in sustainable land use planning (BFF and SLF, 1984; Loat and Petrascheck, 1997; Lateltin et al., 1997). Towards the end of the nineties, based on the work of Wilhelm (1997), two federal guidelines presenting practical oriented methods for the risk analysis of gravitational natural hazards and the economic optimisation of mitigation measures were published in Switzerland (Borter, 1999; Borter and Bart, 1999; Wilhelm, 1999). On the international level, the results of the International Decade for Natural Disaster Reduction (IDNDR) paved the way for an increasing awareness of natural hazard risks and several authors considered the risk concept as a key component for dealing with natural hazards (e.g., IUGS, 1997).

Natural hazard practitioners such as foresters, civil engineers and civil protection officers quickly realized that these new methods for risk analysis (Borter, 1999; Borter and Bart, 1999; Wilhelm, 1999) required a large amount of data that was often not available. Therefore, an additional method was developed, which include the analysis of hazards on existing data as well as expert judgements and local experiences gained in workshops with experts, practitioners, and regional representatives of the population. Based on this so-called "pragmatic approach" (Bähler et al., 2001), the Swiss Federal Office for Civil Protection in collaboration with the Swiss Federal Office for the Environment developed an e-learning platform and a calculation tool provided

Published by Copernicus Publications on behalf of the European Geosciences Union. 


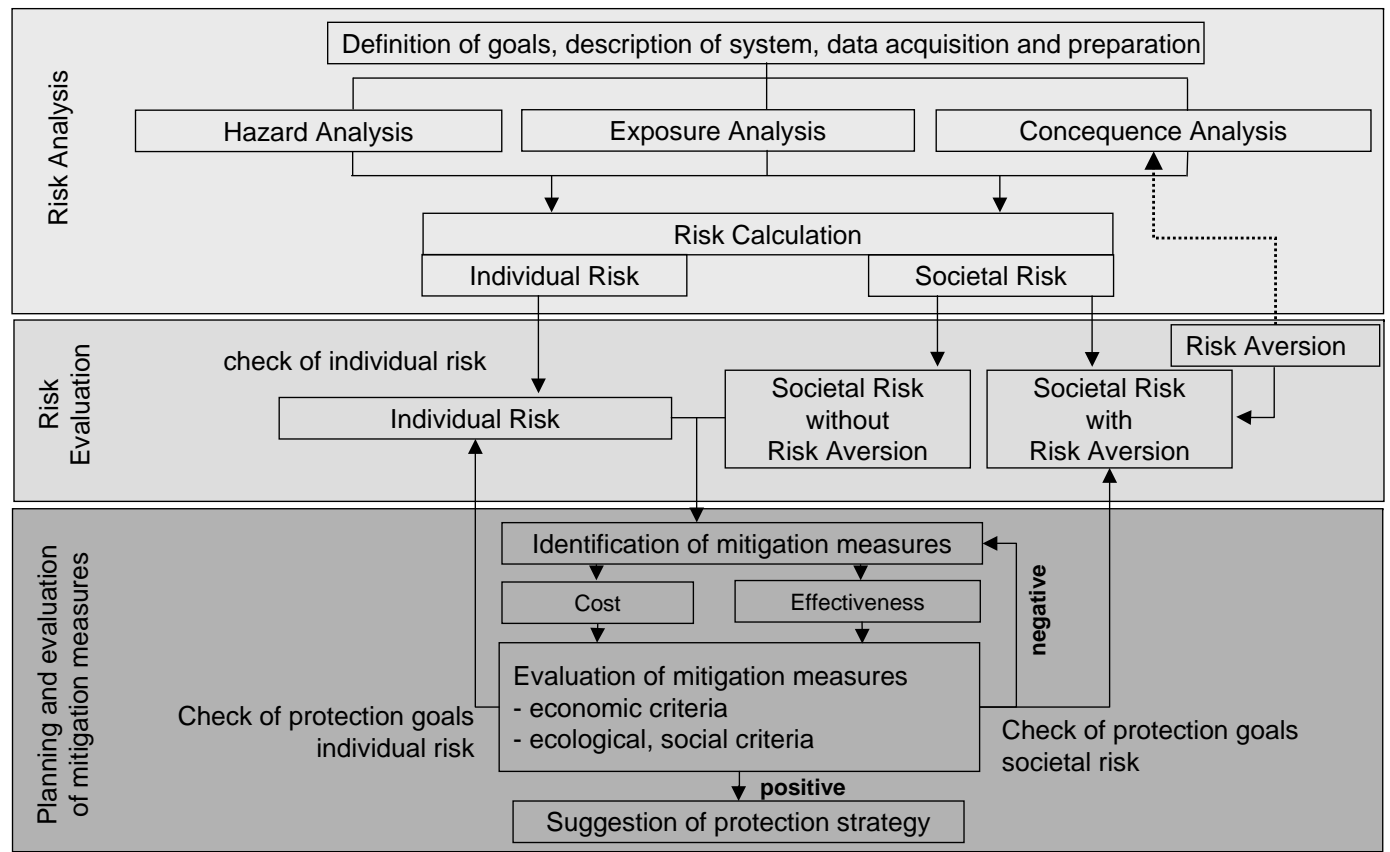

Fig. 1. Illustration of the risk concept.

on a CD-ROM that allows for a simplified risk analysis (BUWAL, BABS, BWG, 2005). The success of this tool and its broad use in the education of students and practitioners in Switzerland and abroad (e.g. the tool was translated into Thai) led to the development of the online-software "RiskPlan 2 Online". Risk-Plan 2 Online can after registration at www.riskplan.admin.ch be freely accessed. The background and the general setup of this tool, which is available in German, French, English and Chinese, are presented in FOEN and FOCP (2008) and Bründl et al. (2009).

In 1999, several severe natural hazard events occurred in Switzerland (Wilhelm et al., 2000; Bründl and Rickli, 2002), which triggered the further development of refined approaches and instruments for the risk based planning of natural hazard mitigation. Under the impression of these hazard events that had cost more than CHF 3 billion, the Swiss government commissioned the National Platform for Dealing with Natural Hazards PLANAT (in German, "Plattform Naturgefahren") and assigned it the mandate to develop a vision and a strategy for dealing with natural hazards in the future (PLANAT, 2005). This strategy is based on the risk concept and aims at an optimised allocation of financial resources by reducing risk with a given relation of risk reduction cost, also called the marginal-cost criterion (Bohnenblust and Slovic, 1998; Ammann, 2006; Bründl et al., 2006; Fuchs et al., 2007). Among other open issues the strategy has suggested to develop a guideline, which illustrates the application of the risk concept to common natural hazards in Switzerland. This guideline, which has been developed over the last two years under the name "RIKO", will be presented in the next section of this paper.

Changes in the Swiss subsidy system, that came into operation with the 1st of January 2008, forced the Federal Office for the Environment and the Swiss cantons, as responsible legal bodies for the protection against natural hazards, to prioritise among mitigation projects in order to respond to limited financial resources. Therefore, they initialised in 2006 the development of a project assessment tool, which would allow prioritising among natural hazard mitigation projects according to their cost-effectiveness. This approach is well in line with the development in other Alpine countries, where decision support tools are developed and introduced into practice (e.g, BLFUW, 2006, 2009; Gamper et al., 2006). This project assessment tool, named "EconoMe", will be presented in the third section of this paper. We will demonstrate the application of the tool by a case study example to ease the understanding of the workflow.

First experiences with earlier guidelines by Borter (Borter, 1999; Borter and Bart, 1999) and Wilhelm (Wilhelm, 1999) showed that the acceptance and particularly the subsequent application by the practitioners have been limited and that these guidelines have so far not been applied in a consistent manner. The results of risk analyses with these guidelines were not comparable to each other (Winkler, 2002, 2003). These experiences suggest that a target-oriented and pragmatic introduction of the new tools is the most important point of successful risk assessment tools. A third goal addressed in the fourth section of this paper is therefore to 
report on the development of these instruments and to discuss the process of their introduction to the community of natural hazard practitioners.

\section{The guideline RIKO}

\subsection{Introduction}

RIKO provides a documentation of the theoretical background and a guideline to the practical application of the risk concept (Fig. 1), which serves as the basis of the Swiss National Strategy against Natural Hazards (PLANAT, 2005). The guideline consists of two parts (Fig. 2). Part A of the guideline presents the risk concept in general and serves as the theoretical backbone that facilitates the knowledge required for the adequate use of the risk assessment tool EconoMe. In Part B, peculiarities of different natural hazard processes are described and their inclusion into the risk assessment and the evaluation of mitigation measures is exemplified by corresponding case studies for all hazard processes (Bründl, 2009).

The heart of the guideline is a very detailed step-by-step procedure for the risk-based planning and evaluation of natural hazard mitigation projects, which consists of three steps: the risk analysis task, the risk evaluation task and the risk management task (Fig. 1). Following Kaplan and Garrick (1981), the risk concept is meant to answer the following guiding questions: "What can happen?", "What may happen?" and "What needs to be done?". In the following subsections we will specify what we mean by these questions.

\subsection{Risk analysis}

\subsubsection{Hazard analysis}

The key element of each risk analysis is the hazard analysis. Basic information upon the hazard process can be taken from terrain analysis, topographic and geological maps, aerial photographs and satellite images as well as from event inventories and historical chronicles. The physical impacts of the hazard are derived from a process analysis, which can be enhanced by physical modelling. The results of the hazard analysis are displayed in intensity maps for each hazard scenario, which indicate at which locations a certain physical impact (e.g., pressure, velocity or inundation depth) is to be expected during a reference period.

\subsubsection{Exposure analysis}

In the exposure analysis persons and assets at risk are identified and their number, type, value and probability of exposure is assessed. Exposure varies with different types of objects, which can be either permanent (e.g. buildings) or mobile (e.g. persons on traffic routes). The probability of exposure for persons in buildings is defined by the number of

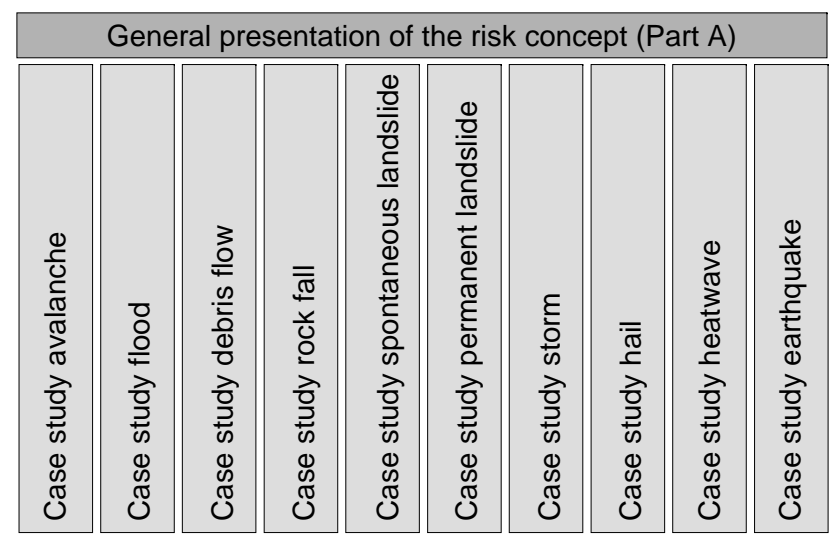

Fig. 2. Content of the guideline RIKO.

hours per day that these persons are present in the building, e.g., for $18 \mathrm{~h} p(e)_{i}=0.75$. The probability of exposed persons in mobile objects $p(e t)$ (e.g., in cars) is determined by the traffic frequency on roads or railways $(M D T)$, the velocity of vehicles $v$ and the length of the endangered traffic line sections $g$ following $p(e t)=(M D T \times g) / v$ (Rheinberger et al., 2009). The number of persons in objects varies in different exposure situations (e.g., fully booked or empty hotel). The consideration of different exposure situations allows accounting for risk peaks.

\subsubsection{Consequence analysis}

The consequence analysis combines the hazard and exposure analysis yielding the expected damage or loss including all considered scenarios. In each scenario, the expected loss is calculated individually for every object at risk. In a second step, the expected loss in this scenario is obtained by summing over the expected loss of the individual objects. Generically, the expected loss of lives $A(N)$ in exposed buildings is calculated as:

$A(N)_{i, j, k}=p(s)_{j} \times p(e)_{i, k} \times N_{i, k} \times \lambda_{i, j}$

where $A(N)_{i, j, k}=$ expected loss of object $i$ in scenario $j$ and exposure situation $k ; p(s)_{j}=$ spatial probability of the process in scenario $j ; p(e)_{i, k}=$ probability of exposure of the object $i$ in exposure situation $k ; N_{i, k}=$ number of persons exposed in object $i$ in exposure situation $k$; and $\lambda_{i, j}=$ mortality rate of persons exposed in object $i$ due to the impact in scenario $j$. If injured persons are considered, the mortality rate has to be replaced by a factor reflecting the probable degree of injury at a defined intensity of the process. Both values can be derived from experiences of comparable events in the past.

The total loss $A(N)_{j}$ of scenario $j$ is then calculated by:

$$
A(N)_{j}=\sum_{k} \sum_{i} A(N)_{i, j, k}
$$




\subsubsection{Calculation of risk}

The risk to a group of persons or objects in the hazard area under investigation is referred to as societal risk. It represents the damage or the fatalities that are statistically expected due to the hazard impact in scenario $j$ and is calculated as the product of the expected damage in a scenario $j$ and the frequency of this scenario according to:

$R_{j}=p_{j} \times A(N)_{j} \quad$ with $\quad p_{j}=P_{j}-P_{j+1}$

with $R_{j}=$ societal risk of scenario $j ; p_{j}=$ frequency of scenario $j ; P_{j}=$ exceedance probability of scenario $j$ and $P_{j+1}=$ exceedance probability of scenario $j+1 ; A(N)_{j}=$ expected loss of scenario $j$. Finally, the total societal risk $R$ can be obtained by summing over all scenarios:

$R=\sum_{j} R_{j}$

The individual risk for persons in highly endangered objects is also looked at. This individual risk expresses the probability for the individual $i$ to die during a reference period (mostly one year) by the specific hazard scenario $j$. It is calculated by:

$r_{i j}=p_{j} \times p(s)_{j} \times p(e)_{i} \times \lambda_{i, j}$

and the total individual risk to an individual $i$ is then:

$r_{i}=\sum_{j} r_{i j}$

with $r_{i j}=$ individual risk of person $i$ in scenario $j ; p_{j}=$ frequency of scenario $j ; p(s)_{j}=$ spatial probability of the process in scenario $j ; p(e)_{i}=$ probability of exposure of person $i ; \lambda_{i, j}=$ mortality of person $i$ in scenario $j ; r_{i}=$ individual risk of person $i$.

\subsection{Risk evaluation}

The societal and the individual risks are compared with predefined safety goals for both risk types (PLANAT, 2005). The individual risk is controlled for whether it complies to the prescribed thresholds. The basic idea behind such thresholds is that the probability of death due to a natural hazard risk beyond self-control should not be higher than $1 \%$ or more of the lowest risk of death within a society (VROM, 1988). For Western societies, these thresholds are in the probability range of $10^{-5}$ /year to $10^{-6} /$ year (see Jonkman et al., 2003, for an overview). The Swiss strategy "Dealing with natural hazards" (PLANAT, 2005) suggests safety goals no higher than $4 \times 10^{-6}<r_{i}<3 \times 10^{-5}$ for involuntarily taken risks .

The evaluation of societal risk is based on the concept that risk can be reduced at proportional cost of mitigation measures (Ammann, 2006; Bründl et al., 2006). "Proportional cost" denotes a relation of risk reduction expressed in monetary units and the yearly cost of mitigation measures. Persons are monetised by the value of statistical life (VSL), which expresses the amount of money a society is willing to pay for averting a fatality (see Hammitt, 2000, for an overview). In Switzerland, we use VSL-values between CHF 5 and 10 million per prevented fatality (PLANAT, 2005). This value corresponds well with VSL values found in the economics literature (Baranzini and Ferro Luzzi, 2001; Leiter and Pruckner, 2008).

\subsection{Planning and evaluation of mitigation strategies}

The goal of any risk assessment is to find an appropriate risk mitigation strategy. Starting from the initial risk, all costeffective measures or combination of measures are evaluated in a stepwise procedure (Fig. 3). By adding risk reducing measures to previous measures and by drawing the amount of risk reduction of measures (effectiveness) and their yearly expected costs into a diagram, the risk-cost diagram can be derived. The evaluation of effectiveness (i.e. the technical feasibility to reduce risk) is based on the analysis of expected consequences after having realised distinct mitigation measures. The costs of mitigation measures $C(y)$ are assessed as annuity value of the initial investment $I(0)$, the annual costs for maintenance $C(m)$ and operation $C(o)$, a residual value $L(n)$ after the lifetime $n$ and an interest rate $p$ for discounting this annuity value following Wilhelm (1999) (Eq. 7):

$C(y)=C(m)+C(o)+\frac{I(0)-L(n)}{n}+\frac{I(0)+L(n)}{2} \times \frac{p}{100}$

In the risk-cost diagram the optimal mitigation strategy can be graphically derived at the tangent point of the risk-cost curve and the marginal-cost criterion line (Fig. 3). The slope of this marginal-cost criterion line equals the ratio of the amount of risk reduction and the associated costs. If the risk is monetised (units of risk reduction and annual cost of measures are the same, e.g. Euro per year), the slope of the marginal-cost criterion line $\beta$ should be equal to -1 or steeper. In other words: $\Delta R / \Delta C \geq 1$ with $\Delta R$ being the risk reduction provided by a specific mitigation strategy and $\Delta C$ being the associated costs of this strategy (Bohnenblust and Slovic, 1998; Bründl et al., 2006; Fuchs et al., 2007).

\subsection{Implementation process of the guideline}

The stepwise structure of the guideline was chosen (I) as it follows the established risk concept and (II) as it is believed that this workflow enables practitioners with different educational backgrounds to conduct risk assessments based on a comparable standard. Hence, the target audience of this guideline are experts in all kind of natural hazards, who work mainly with private companies but might also be staff members of the responsible cantonal and federal authorities. Our experiences made during the development of the guideline show that this methodology provides a common mean for assessing all kind of natural hazard processes in Switzerland, 
although the state of process knowledge and understanding varies from hazard to hazard.

The goal of the guideline, providing a comprehensible documentation of assumptions and methods for complex risk assessment and evaluation of mitigation measures for all kinds of natural hazards, requires defining process specific and site specific values like e.g. the vulnerability of building types or the mortality rate of persons in these buildings. The structured procedure outlined in the guideline serves as basis for the development of software tools, like the tool EconoMe presented in the next section.

\section{The online-tool EconoMe}

\subsection{General setup of the tool}

EconoMe is an online-tool (BAFU, 2009), which can be accessed by authorised users (e.g., experts of engineering companies), who are involved in the planning of mitigation projects subsidised by cantonal and federal resources. The new regulation for subsidy of mitigation measures against natural hazards in Switzerland requires that projects with an investment scope of more than CHF 1 million ( $\sim$ EUR $650000)$ are proofed to be cost-effective. The Federal Office for the Environment uses EconoMe for prioritising among mitigation projects and projects initiated after the 1st of January 2008 have to be assessed by the use of EconoMe.

The workflow of risk assessments in EconoMe follows the risk concept as it is described in the above section (Sect. 2, Fig. 1). The user is guided step-by-step through the risk analysis task, the risk evaluation task and the evaluation of an analysed mitigation project by its cost-effectiveness. The mandatory working procedure consists of the following steps:

1. initialisation of the project;

2. description of the investigated site;

3. hazard analysis and definition of scenarios;

4. determination of the damage potential;

5. consequence analysis before mitigation;

6. calculation of individual risk before mitigation;

7. definition of mitigation measure(s);

8. consequence analysis after mitigation;

9. calculation of individual risk after mitigation;

10. comparison of risk reduction and cost and finalisation of the assessment.

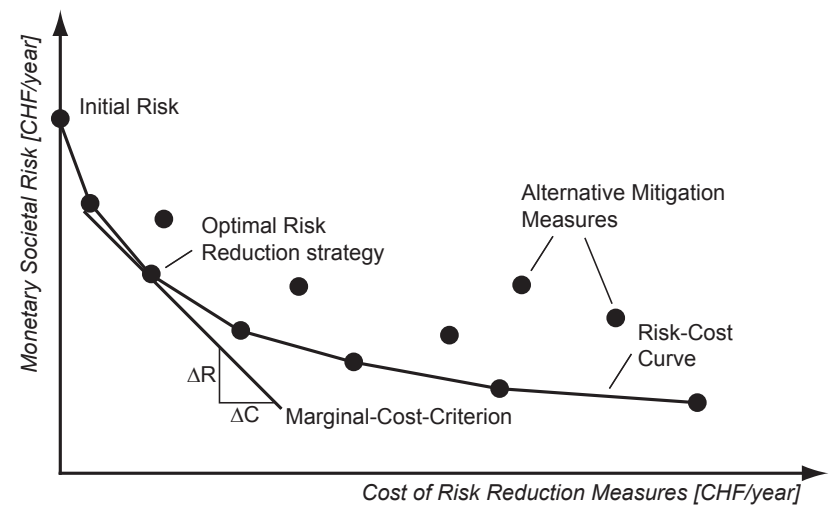

Fig. 3. Exemplary risk-cost diagram which illustrates the optimisation of mitigation measures by using the marginal-cost-criterion. Where the tangent touches the risk-cost curve the economical optimised combination of measures under the given assumptions is suggested (according to Bohnenblust and Slovic, 1998).

The risk analysis (steps 3, 4, 5, and 6) is based upon intensity maps of the investigated process for different scenarios (e.g., 30-, 100-, and 300-year return periods according to Swiss guidelines (BFF and SLF, 1984; Loat and Petrascheck, 1997; Lateltin et al., 1997)). The considered scenarios are fixed in agreement with the contracting authorities and the intensity maps are created aside from EconoMe. Exposed objects are identified individually. The potential damage is determined for every single object as a product of the overlay of the intensity maps with exposed objects considering the spatial probability of the process, the probability of exposure of an object, the number of exposed persons or the value of exposed objects, and the vulnerability of objects or the mortality rate of persons, respectively, according to Eq. (1); identical objects can be summarized to object groups. The values for the vulnerability of objects, the mortality rate of persons and the spatial probability of processes are predefined in the tool and cannot be changed by the user. This guarantees that users rely on the same basis values in their risk assessments and it facilitates the comparison between mitigation projects for only one site and among different sites by the subsidising authorities. In the actual version of EconoMe only the structural vulnerability of objects is considered and other components like socio-economic vulnerability is excluded. The monetary values of objects are also predefined, but can be adapted to regional or site-specific characteristics. However, changing the input values must be referenced and are documented in the program.

The total risk is calculated by integrating the potential damages over all objects, all exposure situations and all considered scenarios following Eqs. (2), (3), and (4). The calculated risk, denoted as societal or collective risk, is based on the assumption that no mitigation measures are taken. Beside the societal risk, the individual risk is calculated for 


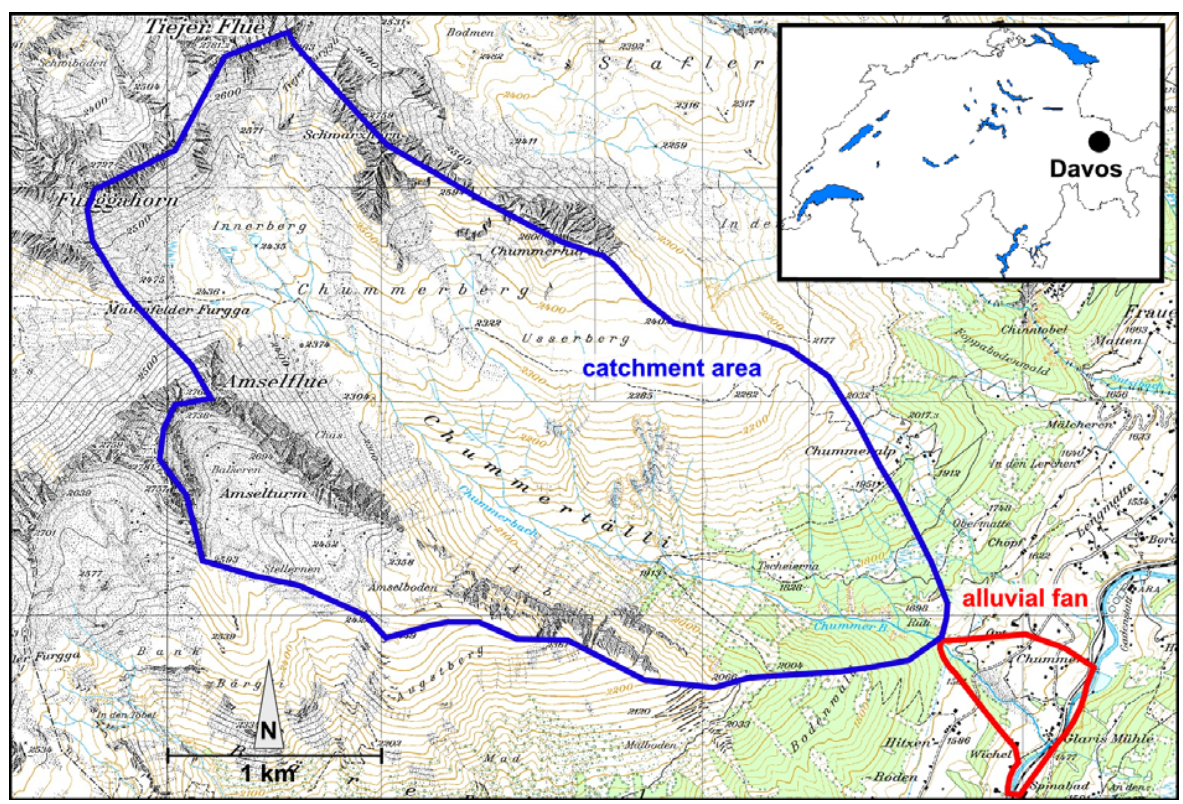

Fig. 4. Overview on the catchment "Chummerbach", Davos; (c) 2008 swisstopo (JD082774).

all objects in which persons are present. Values of individual risks above $1 \times 10^{-4}$ are indicated in red, values between $1 \times 10^{-4}$ and $1 \times 10^{-6}$ are indicated in yellow and values below $1 \times 10^{-6}$ are marked in green colour as an indicator whether the protection goals suggested by the National strategy are violated or not (PLANAT, 2005; Bründl, 2009). After this step, both types of risk are calculated under consideration of the regarded mitigation measures (steps 7, 8, 9). The annuity costs of mitigation measures are calculated according to Eq. (7) (Wilhelm, 1999).

The result of a risk assessment consists of the benefit-cost ratio, whereby the benefit is assumed to equal the risk reduction (step 10). Only mitigation projects that have a benefitcost ratio $\geq 1$ are considered being cost-effective. In order to improve the handling of the tool, the system automatically documents the assumptions made and the results of each risk assessment in a pdf-file.

\subsection{Implementation process of the tool}

EconoMe is an advancement of an existing tool to assess the cost-effectiveness of mitigation projects based on earlier guidelines published by the Federal Office of the Environment (Borter, 1999; Borter and Bart, 1999). Because the target group of EconoMe are natural hazard experts in consulting companies and staff members of cantonal and federal authorities, representatives of these user groups were involved in all phases of the development and the deployment of EconoMe within a project expert group. Frequent meetings with this project expert group ensured that the software addresses the needs of the relevant actors and target groups.
After the development and testing phase, EconoMe was introduced to the end-users during several one-day education and training courses. This was considered to be one essential part of the development process. Since March 2008, EconoMe has been used by practitioners and feedback on the usability of the tool has so far been positive. Particularly, the structured application has been commended and this is illustrated in the next section by a case study example that assesses the risk of a torrent prone to debris flows and floods.

\section{Application of EconoMe - case study "Chummer- bach"}

The Chummerbach is a torrent prone to debris flows near Davos, in the south-east of Switzerland (Fig. 4). A previous case study on this torrent (Romang, 1999a,b) provides excellent data that can be used for presenting the structured risk assessment and the evaluation of cost-effectiveness of mitigation measures.

\subsection{Initialisation of the project}

On the 15th of August 1998, a local storm event with a total precipitation of approximately $100 \mathrm{~mm}$ within $2 \mathrm{~h}$ (according to rainfall radar measurements by MeteoSwiss) triggered heavy erosion in the Chummerbach channel leading to debris flows with a total volume of $50000 \mathrm{~m}^{3}$. The debris flow deposition as well as the subsequent flooding and erosion on the alluvial fan caused severe damages to buildings, traffic lines and agriculture, which summed up to CHF 4 million 
( $\sim$ EUR 2.6 million). This event initiated in-depth studies of the hazards and risks associated with debris flows as well as of appropriate mitigation strategies.

\subsection{Description of the investigated site}

The alluvial fan of the Chummerbach torrent is dominated by agricultural use. It is rather sparsely populated (Fig. 4), especially in comparison to the nearby town of Davos. The catchment area of $6 \mathrm{~km}^{2}$ is covered mainly by pastures. Further, the lower part of the catchment is covered by forests and the upper part by rocks (Fig. 4). The average altitude of the catchment is approximately $2300 \mathrm{~m}$ a.s.l.; $80 \%$ of the area is inclined between 10 and $40 \%$, with an average of $25 \%$. The channel of the torrent follows a geological border: the orographical right-hand side is dominated by limestone formations with karst phenomena and remarkable scree slopes, whereas the left-hand side consists of Permian and Triassic sediments with variable hydrogeological and geotechnical properties, covered mostly by moraines. As a consequence of this geological setting, slope instabilities are widespread on the left-hand side. In the 1998 event, these slopes contributed significantly to the debris load in the channel.

\subsection{Hazard analysis and definition of scenarios}

The hazard assessment was carried out on the basis of the Swiss recommendations for flood hazard mapping (Loat and Petrascheck, 1997). Three scenarios with different statistical return periods were defined (Table 1). The peak discharge was estimated by using different well-established estimation formulas (BWG, 2003). The potential volumes of debris flow scenarios were defined by an intensive field assessment that considered the general geomorphological features in the catchment and the channel as well as the results of the analysis of the 1998 event. The probability of the different scenarios was set on the basis of a back calculation of the 1998 event. By comparing the characteristics of this event with basic information such as the statistical analysis of precipitation data from the nearby gauging stations or the scarce information on past events, the statistical return period of the event was estimated to be at least 100 years.

On the basis of the defined scenarios, intensity maps were created illustrating the degree of hazard for standard return periods (Fig. 5). The intensity zones were delineated regarding the geomorphology of the alluvial fan and the mapping of the 1998 event. Models such as Flo-2D (O'Brien et al., 1993) were not yet commonly used at that time and were therefore not applied to Chummerbach.

\subsection{Determination of the damage potential}

The damage potential within the endangered area on the alluvial fan was limited to:
Table 1. Water discharge and debris volume expected at the fan for three defined scenarios in Chummerbach.

\begin{tabular}{lcr}
\hline $\begin{array}{l}\text { statistical } \\
\text { return period }[\mathrm{y}]\end{array}$ & $\begin{array}{c}\text { peak discharge } \\
{\left[\mathrm{m}^{3} / \mathrm{s}\right]}\end{array}$ & $\begin{array}{r}\text { total volume } \\
\text { of debris }\left[\mathrm{m}^{3}\right]\end{array}$ \\
\hline 30 & 13 & 20000 \\
100 & 18 & $40000-45000$ \\
300 & 24 & $50000-60000$ \\
\hline
\end{tabular}

- 21 buildings (a restaurant, residential buildings, and agricultural buildings);

- $1.5 \mathrm{~km}$ of roads (in particular, a principal road crossing the fan on its lower end);

- $0.7 \mathrm{~km}$ of a railway (with limited traffic); and

- 20 hectares of agricultural land.

These objects were classified directly in the field, and their values were obtained from predefined values in EconoMe, summing up to a total of CHF 22 million.

The average total number of exposed persons in all buildings was 65. It was supposed that people would be present in the buildings for $18 \mathrm{~h}$ a day, which resulted in a probability of presence of 0.75 . In order to calculate the exposure of persons on roads and in trains, different parameters such as the daily frequency of traffic, the velocity of the vehicles, and the length of the endangered sections were estimated.

\subsection{Consequence analysis before mitigation}

The expected losses were calculated by combining the hazard and exposure analysis for each scenario. In addition, permanent objects were distinguished from mobile objects and material assets from persons. The vulnerabilities of the objects were obtained from EconoMe (Table 2). The expected losses summed up to CHF 1.4 million, 4.3 million, and 7.1 million for a 30-year, a 100-year, and a 300-year event, respectively. Finally, the frequency-extent diagram was derived from the expected losses and the frequency of the underlying scenarios. The total societal risk including all scenarios was calculated at CHF 86000 per year, whereby the loss of lives was monetised with CHF 5 million per fatality, which is a standard value in Switzerland (Bründl et al., 2006).

Different hazard scenarios contributed similarly to the total societal risk. However, although the expected loss was considerably smaller in the case of a 30-year event than in the other cases, it contributed most to the total risk due to its higher probability. In frequent as well as in rare events, the damage to material assets was dominating. Overall, the risk for material assets was six times higher than the monetised risk for persons. Hence, it can be concluded that the societal risk for persons was rather low. 


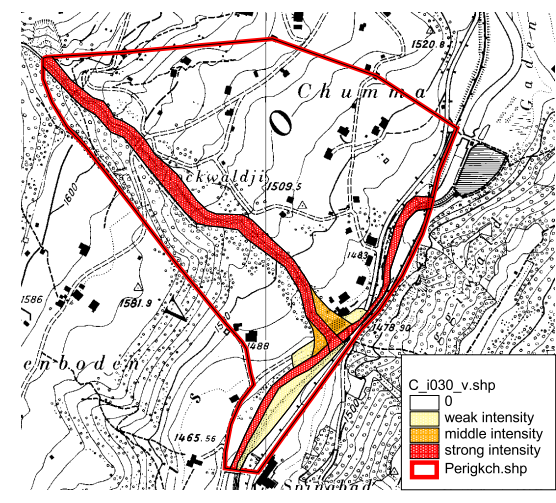

(a)

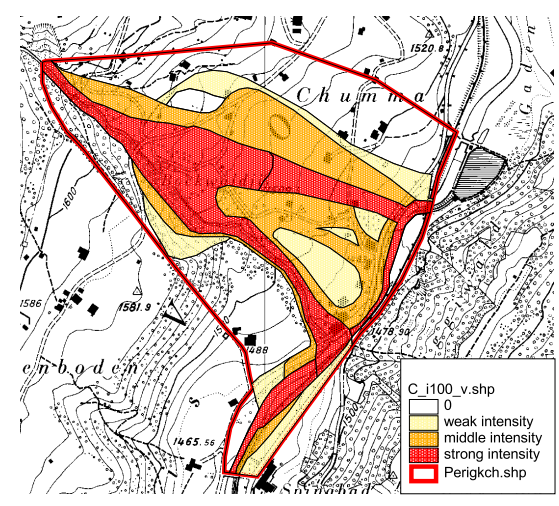

(b)

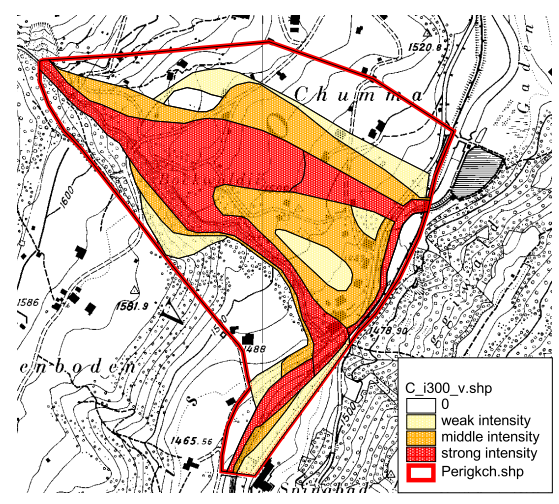

(c)

Fig. 5. Intensity maps without considering measures for a 30-year (a), a 100-year (b), and a 300-year event (c), respectively.

\subsection{Calculation of individual risk before measures}

Individual risks were calculated for selected persons, who are supposed to have a higher probability of exposure to hazard events. The result showed that in a few buildings as ell as on highly exposed road sections the individual risks were considerably higher than $1 \times 10^{-5}$, which is the upper threshold for involuntary individual risks in Switzerland (PLANAT, 2005).

\subsection{Definition of mitigation strategies}

Several mitigation measures were studied, focussing mainly on structural mitigation measures. Finally, the following six alternatives were analysed in detail:

1. Construction of a series of check dams in the middle reach of the channel in order to stabilise the bed and prevent further erosion;

2. Stabilisation of the banks and the slopes on the left-hand side in the lower reach of the channel in order to decrease slope movements and prevent further erosion;

3. Construction of a medium-sized retention basin $\left(30000 \mathrm{~m}^{3}\right)$ at the fan apex in order to retain a considerable part of the debris load up to a 100-year event;

4. Local protection of the most exposed buildings in order to increase their resistance and protect the people inside;

5. Construction of a maximal-sized retention basin $\left(50000 \mathrm{~m}^{3}\right)$ at the fan apex in order to retain almost all the debris up to a 300-year event;

6. Combination of a medium-sized retention basin and of local protection.
The effectiveness of all these alternatives in terms of risk reduction was analysed by using an approach outlined in Romang et al. (2003) for the assessment of structural mitigation measures. The result of this assessment are intensity maps. In addition, the cost of these alternatives was estimated on the basis of standard cost values for construction works, the expected lifetime of measures, and on empirical values for annual maintenance and repair costs.

\subsection{Consequence analysis after mitigation}

On the basis of the intensity maps (after mitigation), which were elaborated for all the alternatives mentioned above, we calculated the expected risks while accounting for the corresponding risk reductions brought about by the analysed mitigation alternatives. The risk reduction varied from 23\% (alternative 4) to $93 \%$ (alternative 5) (Table 3).

\subsection{Calculation of individual risk after mitigation}

The calculation of the individual risk showed that all alternatives would reduce risks to a value below $1 \times 10^{-5}$ that complies with the Swiss safety goals.

\subsection{Overview of the risk reduction and costs and selec- tion of the most appropriate mitigation strategy}

The benefit-cost ratio, which has to be $\geq 1$ in order to fulfil the economic criteria of EconoMe, was calculated for all mitigation alternatives described above (Table 3). The benefit was calculated as difference of societal risk without consideration of mitigation measures minus the societal risk considering mitigation measures. The annual cost of mitigation measures were calculated following Eq. (7).

This risk assessment clearly showed that risk mitigation strategies in the channel upstream (alternatives 1 and 2) don't fit the the economic criteria in EconoMe. Further, local 
Table 2. Parameters for vulnerability and mortality rates for different intensities for the processes flood and debris flow. The values have been fixed based on experiences from comparable, past events. Source: www.econome.admin.ch.

\begin{tabular}{lcccccc}
\hline & \multicolumn{3}{c}{ vulnerability } & flood & mortality rate \\
& weak & middle & strong & weak & middle & strong \\
\hline residential buildings & 0.02 & 0.2 & 0.3 & $2 \times 10^{-7}$ & $2 \times 10^{-5}$ & $6 \times 10^{-4}$ \\
agricultural buildings & 0.05 & 0.3 & 0.4 & $5 \times 10^{-7}$ & $3 \times 10^{-5}$ & $4 \times 10^{-4}$ \\
restaurant & 0.02 & 0.2 & 0.3 & $2 \times 10^{-7}$ & $2 \times 10^{-5}$ & $6 \times 10^{-4}$ \\
road & 0 & 0.01 & 0.1 & 0 & $1 \times 10^{-10}$ & 0.001 \\
railway & 0.5 & 0.8 & 1 & 0 & $8 \times 10^{-9}$ & $1 \times 10^{-8}$ \\
\hline
\end{tabular}

\begin{tabular}{lcccccc}
\hline & \multicolumn{5}{c}{ vulnerability } & \multicolumn{3}{c}{$\begin{array}{c}\text { debris flow } \\
\text { mortality rate } \\
\text { middle }\end{array}$} & strong \\
\hline residential buildings & 0.02 & 0.4 & 0.6 & $2 \times 10^{-7}$ & $4 \times 10^{-3}$ & 0.06 \\
agricultural buildings & 0.05 & 0.2 & 0.5 & $5 \times 10^{-7}$ & $2 \times 10^{-3}$ & 0.05 \\
restaurant & 0.02 & 0.4 & 0.6 & $2 \times 10^{-7}$ & $4 \times 10^{-3}$ & 0.06 \\
road & 0 & 0.2 & 0.5 & 0 & 0.1 & 0.4 \\
railway & 0.5 & 0.6 & 1 & 0 & $6 \times 10^{-4}$ & 0.01 \\
\hline
\end{tabular}

mitigation measures (alternative 4) have the best benefit/cost ratio. The two different retention basins (alternatives 3 and 5) are similar with regard to their cost-effectiveness; the decrease in risk with an increase in the size of the basin is equalised by increasing costs. Hence, alternative 4 seems to be the most favourable solution. However, it should not be forgotten that uncertainties in the whole risk assessment procedure are quite remarkable and that probably not all of the differences in Table 3 are significant.

Finally, alternative 6 was realised in the field. Besides the fact that this is a cost-effectiveness solution, the two arguments that additionally supported this decision are the following: First, the risk reduction of alternative 6 (as well as that of 3 and 5) is considerably higher than that of alternative 4 . Therefore, a considerably higher benefit can be achieved implementing alternative 6 rather than alternative 4 . Second, the combination of measures in this example provides redundancy and additional safety.

This is a welcomed effect, because it helps to reduce uncertainties about the effectiveness of single mitigation measures. Alternative 6 is the only combination of measures in the analysed portfolio. Hence, the choice and implementation of alternative 6 is reasonable.

\section{Discussion}

The introduction of new methodologies into the community of natural hazard practitioners is a time-consuming process (White et al., 2001). At the end of the 20th century sev- eral new instruments were issued by the federal authorities in Switzerland. The guidelines for hazard mapping were published in 1997. Only two years later, the first guidelines for risk analysis for practitioners were published. Investigations after three to five years indicated that these methods were either not used or that they were applied in an inconsistent manner, so that results from risk assessments could not be compared to each other (Winkler, 2003; PLANAT, 2005). Although, there were some instruments for risk-based planning available four years ago, investigations suggest that riskbased planning was not anchored in the community of natural hazard practitioners at that time (Hollenstein et al., 2004).

One of the reasons might be that risk based planning was not required by federal and cantonal authorities (Bischof et al., 2009). Another reason might be that these instruments were not sufficiently well introduced to practitioners. Other examples such as the current practice in avalanche warning (Bründl et al., 2004) show that education courses are an essential part in introducing new methods and techniques to the community of natural hazard practitioners. Education courses are one way of risk communication and may play a central role within integral risk management (IRGC, 2005).

A second reason for the less consistent way in which the instruments by Borter and Wilhelm (Borter, 1999; Borter and Bart, 1999; Wilhelm, 1999) were used might be, that they were not available as software tools. A pre-defined clear workflow as it is implemented in EconoMe allows a consistent application of the risk concept. Pre-defined values for the spatial probability, the vulnerability and the mortality rate for persons enable comparable results. The clear indication 
Table 3. Risk reduction and cost of six alternatives of structural mitigation measures in Chummerbach.

\begin{tabular}{lcccr}
\hline alternative & \multicolumn{2}{c}{ risk reduction } & costs & benefit / cost \\
& CHF/y & \% of initial risk & CHF/y & $\begin{array}{r}\text { ratio } \\
\hline \text { 1: check dams }\end{array} 2^{\prime} 000$ \\
2: bank stabilisation & $22^{\prime} 000$ & 26 & $65^{\prime} 000$ & 0.45 \\
3: medium-sized retention basin & $63^{\prime} 000$ & 73 & $25^{\prime} 000$ & 0.88 \\
4: local protection & $20^{\prime} 000$ & 23 & $15^{\prime} 000$ & 1.15 \\
5: maximum-sized retention basin & $80^{\prime} 000$ & 93 & $65^{\prime} 000$ & 1.33 \\
6: combination of 3 and 4 & $66^{\prime} 000$ & 77 & $65^{\prime} 000$ & 1.23 \\
\hline
\end{tabular}

of changes in basic values by the user improves the comprehensible assessment of the results from the risk assessment. The case study "Chummerbach" demonstrated that the structured workflow led to comprehensible results. The final benefit-cost ratio depends on the assumptions and parameters in the risk assessment and the estimated effectiveness of mitigation measures. Examples from other studies indicated that the benefit-cost ratio can vary up to several factors due to changed values for vulnerability and mortality rate (Bründl et al., 2009). In the actual version of EconoMe the uncertainties of input data are not considered. It will be one of the next steps in the further development to integrate the uncertainties of parameters and to communicate the effects to the end-users.

A third reason, which might support the introduction and the application of instruments and guidelines into practice is simply that it is mandatory for new projects above an investment sum of $\geq$ CHF 1 million, which forces all cantonal authorities to use EconoMe for economic assessment of mitigation projects. One year after the introduction of EconoMe over 300 projects could be found in the database (BAFU, 2009). The first experiences during the introduction of EconoMe to the community of natural hazard practitioners indicate that practitioners start only to deal with risk based decision making when they were obliged to.

Last but not least, every innovation or new technology takes some time for being applied. The guideline for regarding avalanche hazard in land use planning in Switzerland was published in 1984 (BFF and SLF, 1984) and those for integrating flood and mass movement hazard into land use planning in 1997 (Loat and Petrascheck, 1997; Lateltin et al., 1997). The state of hazard mapping in Switzerland on January 2008 shows that for $50 \%$ of the potential avalanche endangered areas hazard maps are existing and integrated into land use planning. However, this holds only for $20 \%$ of the areas endangered by floods and mass movements (BAFU, 2008). This comparison supports the statement of White et al. (2001) that long-term improvements in natural hazard management could be observed only over decades. Although their observations mainly refer to the situation in the United States, we can expect that the integration of the risk concept into the natural hazard management practice in Switzerland will also take some more years.

With the development of the guideline RIKO and the software tool EconoMe, a knowledge exchange process was initiated among scientists and practitioners with both groups being integrated in the development process. During the introduction of EconoMe by education courses, some potential for improvements and removing of teething troubles was detected. It soon became clear that EconoMe significantly contributed to the implementation of the risk concept into practice. The fact that it is mandatory for projects with an investment of $\geq$ CHF 1 million ensures that practitioners have to deal with the application of the risk concept. The use of EconoMe in their daily work helps also to improve the tool by practical experiences. Therefore, it is necessary that knowledge between developers and users are regularly exchanged. This, and the integration of new functionalities into EconoMe (like e.g., an illustration of uncertainties and the integration of spatial information using GIS-techniques) will pave the way for an improved, widely accepted tool for the risk-based planning and evaluation of mitigation projects.

The goal of introducing the risk concept as a management basis for dealing with natural hazards was to optimize the allocation of financial resources. The argumentation for a priorisation of mitigation measures in certain regions becomes comprehensible when they are based on comparable risk assessments. The architecture and the workflow in EconoMe with pre-defined factors for calculation allows that results provided by different users can be better compared, although uncertainties especially concerning the hazard assessment still remain. The application of the workflow of EconoMe illustrated by the case study Chummerbach indicated that the decision on the realisation of mitigation measures becomes more obvious. However, results can be misleading when they are produced by insufficiently qualified users. This undesired effect could be addressed by requiring that only persons, who have passed certain education courses, are permitted to evaluate mitigation projects with EconoMe.

Cost-benefit and cost-effectiveness analysis have become state-of-the-art for evaluating mitigation measures against natural hazards in many countries (see e.g., Whalen et al., 
2004; Gamper et al., 2006; Pinelli et al., 2007; Holub and Fuchs, 2008; BLFUW, 2006, 2009). One tool similar to EconoMe is a calculation program used in Austria based on Microsoft Excel @ (BLFUW, 2006, 2009). Both tools allow the calculation of the economic efficiency, but there are some differences, which will be shortly described in the following paragraphs.

In the Austrian tool the initial assumptions are that mitigation measures will fulfil their function either for 40 or 80 years and that they will protect against a design event with a recurrence interval of 150 years. The results of the hazard analysis are approximated with an event factor $E$ representing the contribution of scenarios to the expected damage extent, and a process factor $P$ estimating the part of hazard zones, which is affected by the process. In EconoMe the service life of measures depend on the type of measures, which could be e.g., 80 years for an avalanche supporting structure or only 20 years for an alarm system. The result of the hazard analysis is illustrated with intensity maps for different scenarios but with defined intensity classes according to the Swiss recommendations for hazard mapping (BFF and SLF, 1984; Loat and Petrascheck, 1997; Lateltin et al., 1997). A second difference is the calculation of damage and risk. In the Austrian tool the damage is estimated based on a damage factor $S$ expressing the damage ratio related to the estimated replacement value of an object. Hence, the risk expressed as probable annual damage is not calculated. The damage factors are based on the values published by Borter (1999), Borter and Bart (1999), and Romang (2004). These values are also the basis for the vulnerability factors used in EconoMe for the calculation of the probable annual damage, i.e. the societal or collective risks. The risk is calculated without and with consideration of measures, wheras only direct damages are included. In the Austrian tool the benefit of measures includes the reduction of direct and indirect damages (e.g. business interruption) and is directly put in relation to the cost of measures yielding the cost-benefit-ratio. Both, the benefit and the cost are discounted. However, prevented human fatalities are not explicitly considered as in EconoMe (i.e., monetised with 5 million CHF per prevented fatality) but taken into account as intangible benefit by a weigthing factor as for other factors like e.g. safety feeling or availability of traffic routes.

In summary, the Austrian tool and EconoMe are comparable regarding their general goal but they mainly differ in the way the results are produced. The definition of benefit in the Austrian tool is more broad than in EconoMe, since it includes also indirect consequences. The setup of EconoMe is to some extent more flexible. The only parameters which are specific to Switzerland are the monetary values of objects and the calculation factors vulnerability and mortality rates. However, the general methodology is transferable to other processes and to other countries. With slight modifications, EconoMe could also be used outside of Switzerland.

\section{Conclusions and outlook}

The risk concept as a framework for risk-based planning and evaluation of natural hazard mitigation has been introduced in Switzerland over the last ten years. New political conditions for the subsidy of mitigation measures and limited public budgets have led to the development of the guideline RIKO and the software tool EconoMe in the last three years. Our experiences indicate that a user-friendly software tool with involvement of the end-users in the development process and an introduction to practitioners with education courses are crucial steps for a successful implementation of the risk concept into practice.

It is of major interest for the Federal Office for the Environment FOEN, who is responsible for the development of EconoMe, to continously improve the tool and to further strengthen the acceptance of EconoMe. The next steps will be the integration of missing components of the risk concept (as presented in Sect. 2 for RIKO) and the consideration of the requirements of users, mainly working in cantonal authorities and engineering companies. An important issue is the integration of confidence intervals for the benefit-cost ratio reflecting the uncertainty of input data (e.g., vulnerability of buildings, mortality rate of persons). This would allow decision makers at the federal and cantonal authorities for better interpreting the benefit-cost ratio of mitigation projects with respect to prioritisation. A further extension of EconoMe could be the integration of further aspects of benefit, like e.g. less closing days for a traffic route because of protection measures. Finally, the integration of methods for economic optimisation of mitigation measures can help to assure that the complete risk concept as outlined in the guideline RIKO will be available for practical application.

Acknowledgements. We thank the National Platform Natural Hazards PLANAT, the Federal Office for Environment FOEN and the Federal Office for Civil Protection FOCP for their financial support of this work. Parts of this paper were also supported by the EU FP6 STREP project "IRASMOS" (Contract No. 081412). We acknowledge the excellent programming work by Peter Gutwein (GRSoft, www.grsoft.ch) and his patience in various difficult discussions of how a user-friendly risk management software could be realised. We also want to thank Bernhard Krummenacher and Fabian Dolf of GEOTEST AG, Cornelia Winkler of glenz, walther und winkler AG and Hans M. Merz, Ernst Basler + Partner AG for valuable discussions. Finally, we thank J.-M. Tacnet, an anonymous reviewer and the editor for their helpful comments.

Edited by: M. Mikos

Reviewed by: J.-M. Tacnet and another anonymous referee 


\section{References}

Ammann, W.: The Risk Concept, in: Risk 21 - Coping with Risks due to Natural Hazards in the 21st Century, edited by: Dannenmann, S., Ammann, W., and Vulliet, L., 3-23, Taylor \& Francis, London, 2006.

BAFU: Website Federal Office for the Environment, http://www. bafu.admin.ch/umwelt/daten/04544/index.html?lang=de, access 6 October 2008, 2008.

BAFU: EconoMe-Wirtschaftlichkeit von Schutzmassnahmen gegen Naturgefahren., www.econome.admin.ch, access 6 May 2009, 2009.

Bähler, F., Wegmann, M., and Merz, H.: Pragmatischer Ansatz zur Risikobeurteilung von Naturgefahren, Wasser, Energie, Luft, 93, 193-196, 2001.

Baranzini, A. and Ferro Luzzi, G.: The Economic Value of Risks to Life: Evidence from the Swiss Labour Market, Swiss Journal of Economics and Statistics, 137, 149-170, 2001.

BFF and SLF: Richtlinien zur Berücksichtigung der Lawinengefahr bei raumwirksamen Tätigkeiten, EDMZ, Bern, http://www.bafu. admin.ch/php/modules/shop/files/pdf/phpWQ0pcv.pdf, 1984.

Bischof, N., Romang, H., and Bründl, M.: Integral risk management of natural hazards - A system analysis of operational application to rapid mass movements, in: Safety, Reliability and Risk Analysis: Theory, Methods and Applications, edited by: Martorell, S., Soares, C. G., and Barnett, J., 4, 2789-2795, CRC Press/Balkema, Leiden, 2009.

BLFUW: Richtlinien für die Wirtschaftlichkeitsuntersuchung und Priorisierung von Massnahmen der Wildbach- und Lawinenverbauung gemäss $\$ 3$ Abs. 2 Z 3 Wasserbautenförderungsgesetz 1985, Bundesministerium für Land- und Forstwirtschaft, Umwelt und Wasserwirtschaft, Sektion Forstwesen, Wien, http: //www.forstnet.at/filemanager/download/33905/, 2006.

BLFUW: Kosten-Nutzen-Untersuchungen im Schutzwasserbau. Richtlinie. KNU gemäss $\$ 3$ Abs. 2 Ziffer 3 WBFG, Fassung Februar 2009, Bundesministerium für Land- und Forstwirtschaft, Umwelt und Wasserwirtschaft, Sektion Wasser, Wien, http:// www.wassernet.at/filemanager/download/26589/, 2009.

Bohnenblust, H. and Slovic, P.: Integrating technical analysis and public values in risk-based decision making, Reliab. Eng. Syst. Safe., 59, 151-159, 1998.

Borter, P.: Risikoanalysen bei gravitativen Naturgefahren107/I-Methode, Umwelt-Materialien 107/I, Bundesamt für Umwelt, Wald und Landschaft, BUWAL, Bern, http://www.bafu. admin.ch/php/modules/shop/files/pdf/phpAy8rtB.pdf, 1999.

Borter, P. and Bart, R.: Risikoanalysen bei gravitativen Naturgefahren-107/II-Fallbeispiele und Daten, UmweltMaterialien 107/II, Bundesamt für Umwelt,Wald und Landschaft, BUWAL, Bern, 1999.

Bründl, M. (Ed.): Risikokonzept für Naturgefahren. Leitfaden, Nationale Plattform für Naturgefahren PLANAT, Bern, http://www. planat.ch/ressources/planat_product_de_1110.pdf (German); http://www.planat.ch/ressources/planat_product_fr_1110.pdf (French); http://www.planat.ch/ressources/planat_product_it_ 1110.pdf (Italian), 2009.

Bründl, M. and Rickli, C.: The storm Lothar 1999 in Switzerland an incident analysis, Forest, Snow and Landscape Res., 77, $207-$ 217, 2002.

Bründl, M., Etter, H.-J., Steiniger, M., Klingler, Ch., Rhyner, J., and Ammann, W. J.: IFKIS - a basis for managing avalanche risk in settlements and on roads in Switzerland, Nat. Hazards Earth Syst. Sci., 4, 257-262, 2004,

http://www.nat-hazards-earth-syst-sci.net/4/257/2004/.

Bründl, M., McAlpin, M., Gruber, U., and Fuchs, S.: Application of the marginal cost-approach and cost-benefit analysis to measures for avalanche risk reduction - A case study from Davos, Switzerland, in: RISK21 - Coping with risks due to natural hazards in the 21 st century, edited by: Dannenmann, S., Ammann, W., and Vulliet, L., 155-168, Taylor \& Francis, London, 2006.

Bründl, M., Krummenacher, B., and Merz, H.: Decision making tools for natural hazard risk management - Examples from Switzerland, in: Safety, Reliability and Risk Analysis - Theory, Methods and Applications, edited by: Martorell, S., Soares, C. G., and Barnett, J., 4, 2773-2779, CRC Press/Balkema, Leiden, 2009.

BUWAL, BABS, BWG: Pragmatisches Risikomanagement - Im Dialog zu mehr Sicherheit., Bundesamt für Umwelt, Wald und Landschaft (BUWAL), Bern, CD-ROM, 2005.

BWG: Hochwasserabschätzung in schweizerischen Einzugsgebieten, no. 4 in Serie Wasser, Bundesamt für Wasser und Geologie, Biel, 2003.

FOEN and FOCP: RiskPlan-Pragmatic Risk Management, www. riskplan.admin.ch, access 5 May 2009, 2008.

Fuchs, S., Thöni, M., McAlpin, M. C., Gruber, U., and Bründl, M.: Avalanche hazard mitigation strategies assessed by cost effectiveness analyses and cost benefit analyses - evidence from Davos, Switzerland, Nat. Hazard., 41, 113-129, 2007.

Gamper, C. D., Thöni, M., and Weck-Hannemann, H.: A conceptual approach to the use of Cost Benefit and Multi Criteria Analysis in natural hazard management, Nat. Hazards Earth Syst. Sci., 6, 293-302, 2006, http://www.nat-hazards-earth-syst-sci.net/6/293/2006/.

Hammitt, J. K.: Valuing mortality risk: Theory and practice, Environ. Sci. Technol., 34, 1396-1400, 2000.

Heinimann, H., Hollenstein, K., Kienholz, H., Krummenacher, B., and Mani, P.: Methoden zur Analyse und Bewertung von Naturgefahren, http://www.bafu.admin.ch/php/ modules/shop/files/pdf/phpc4uQgs.pdf, 1998.

Hollenstein, K.: Analyse, Bewertung und Management von Naturrisiken, vdf Hochschulverlag an der ETH, Zürich, 1997.

Hollenstein, K., Merz, H., and Bähler, F.: Förderung des risikobasierten Planens und Handelns bei der Naturgefahrenabwehr. Schlussbericht, Tech. rep., ETH Zürich Forest Engineering, http://e-collection.ethbib.ethz.ch/eserv/eth:26923/ eth-26923-01.pdf, 2004.

Holub, M. and Fuchs, S.: Benefits of local structural protection to mitigate torrent-related hazards, in: 6th International Conference on Computer Simulation Risk Analysis and Hazard Mitigation, edited by: Brebbia, C. A., 401-411, Cephalonia, GREECE, 2008.

IRGC: Risk Governance: Towards an Integrative Approach, Geneva, white Paper No. 1, 2005.

IUGS: Quantitative Risk Assessment for Slopes and Landslides The State of the Art, in: Landslide Risk Assessment, Proceedings of the International Workshop on Landslide Risk Assessment, edited by: Cruden, D. and Fell, R., 3-12, Balkema, Rotterdam, 1997.

Jonkman, S., Kok, M., and Vrijling, J.: Flood Risk Assessment in the Netherlands: A Case Study for Dike Ring South Holland, 
Risk Analysis, 28, 1357-1374, 2008.

Jonkman, S. N., van Gelder, P., and Vrijling, J. K.: An overview of quantitative risk measures for loss of life and economic damage, J. Hazard. Mater., 99, 1-30, 2003.

Kaplan, S. and Garrick, B.: On the Quantitative Definition of Risk, Risk Analysis, 1, 11-27, 1981.

Lateltin, O., Tripet, J.-P., and Bollinger, D.: Berücksichtigung der Massenbewegungsgefahren bei raumwirksamen Tätigkeiten. Empfehlungen, BUWAL, BWW, BRP, http://www.planat.ch/ ressources/planat_product_de_1032.pdf (German); http://www. planat.ch/ressources/planat_product_fr_1032.pdf (French), 1997.

Leiter, A. and Pruckner, G.: Dying in an Avalanche: Current Risks and Valuation, Tech. rep., Fakultät für Volkswirtschaft und Statistik, University of Innsbruck, http://econpapers.repec.org/ paper/innwpaper/2008-11.htm, 2008.

Loat, R. and Petrascheck, A.: Berücksichtigung der Hochwassergefahren bei raumwirksamen Tätigkeiten. Empfehlungen, BWW, BRP, BUWAL, http://www.planat.ch/ressources/planat_product_ de_1031.pdf (German); http://www.planat.ch/ressources/planat_ product_fr_1031.pdf (French), 1997.

Merz, B. and Emmermann, R.: Dealing with natural hazards in Germany: From reaction to risk management, Gaia, 15, 265-274, 2006.

Merz, H. A., Schneider, T., and Bohnenblust, H.: Bewertung von technischen Risiken. Beiträge zur Strukturierung und zum Stand der Kenntnisse. Modelle zur Bewertung von Todesfallrisiken, vdf Hochschulverlag an der ETH Zürich, Zürich, 1995.

O'Brien, J., Julien, P., and Fullerton, W.: Two-dimensional water flood and mudflow simulation, J. Hydrol. Eng., 119, 244-261, 1993.

Pinelli, J. P., Subramanian, C. S., Garcia, F., and Gurley, K.: A study of hurricane mitigation cost effectiveness in Florida, in: European Safety and Reliability Conference (ESREL 2007), edited by: Aven, T. and Vinnem, J. E., 1505-1509, Stavanger, Norway, 2007.

PLANAT: Strategie Naturgefahren Schweiz. Synthesebericht., Tech. rep., National Platform for Natural Hazards, http://www. planat.ch/ressources/planat_product_de_543.pdf, 2005.

Rheinberger, M. C., Bründl, M., and Rhyner, J.: Dealing with the White Death: Avalanche Risk Management for Traffic Routes, Risk Analysis, 29, 76-94, 2009.

Romang, H.: Gefahren- / Risikobeurteilung Chummerbach, Davos Glaris. Ereigniskataster, Abflussberechnung und Feststoffpotential, Zustand und Wirkung der Schutzmassnahmen, Gefahrenbeurteilung, Risikobeurteilung, Tech. rep., Universität Bern, Geographisches Institut, Bern, 1999a.
Romang, H.: Massnahmenstudie Chummerbach, Davos Glaris. Variantenstudium Schutzmassnahmen, Beurteilung der Wirksamkeit, Abschätzung der Kosten, Tech. rep., Universität Bern, Geographisches Institut, Bern, 1999b.

Romang, H.: Wirksamkeit und Kosten von WildbachSchutzmassnahmen, vol. G 73 of Geographica Bernensia, Verlag des Geographischen Instituts der Universität Bern, Bern, 2004.

Romang, H., Kienholz, H., Kimmerle, R., and Böll, A.: Control structures, vulnerability, cost-effectiveness - a contribution to the management of risks from debris torrents, in: Debris-flow hazards mitigation: mechanics, prediction, and assessment, edited by: Rickenmann, D. and Chen, C., 2, 1303-1313, Millpress, Rotterdam, 2003.

Starr, C.: Social Benefit versus Technological Risk: What is our society willing to pay for safety?, Science, 165, 1232-1238, 1969.

VROM: Dutch National Environmental Plan, 1988.

Whalen, T. M., Gopal, S., and Abraham, D. M.: Cost-benefit model for the construction of tornado shelters, J. Constr. Eng. M.-Asce., 130, 772-779, 2004.

White, G., Kates, R., and Burton, I.: Knowing Better and Losing Even More: The Use of Knowledge in Hazards Management, Environ. Hazard., 3, 81-92, 2001.

Wilhelm, C.: Wirtschaftlichkeit im Lawinenschutz - Methodik und Erhebungen zur Beurteilung von Schutzmassnahmen mittels quantitativer Risikoanalyse und ökonomischer Bewertung, vol. 54, Eidg. Institut für Schnee- und Lawinenforschung SLF, Davos, 1997.

Wilhelm, C.: Kosten-Wirksamkeit von LawinenschutzMassnahmen an Verkehrsachsen 1999. Vorgehen, Beispiele und Grundlagen der Projektevaluation, BUWAL, Bern, 1999.

Wilhelm, C., Wiesinger, T., Bründl, M., and Ammann, W.: The Avalanche Winter 1999 in Switzerland - an Overview, in: Int Conf. Snow Science Workshop ISSW, 8-15, Big Sky, Montana, 2000.

Winkler, C.: Risikoanalysen im Bereich Naturgefahren - Ein Methodenvergleich, Thesis Post Diploma Course NDK, Swiss Institute for Technology ETH, Zurich, 2002.

Winkler, C.: Analyse Vorstudie 431 (2000-2002), Kurzbericht, Tech. rep., Federal Office for the Environment, Bern, 2003. 